\title{
Fungal Contaminants of Spices Used in Tunisia
}

\author{
R. Saidi ${ }^{1,4, *}$, A. Gritli ${ }^{2}$, M. Ben Rhaiem ${ }^{1,4}$, I. Mnejja ${ }^{1}$, B. Jemli ${ }^{3}$ \\ ${ }^{1}$ Military Laboratory of Food Analysis, General Directorate of Military Health, 2001 Tunis, Tunisia. \\ ${ }^{2}$ Military Center for Veterinary Medicine, General Directorate of Military Health, 2001 Tunis, Tunisia. \\ ${ }^{3}$ Laboratory of Parasitology-Mycology, Military Hospital of Tunis, 1008, Monfleury, Tunis, Tunisia. \\ ${ }^{4}$ Department of Biology, Faculty of Sciences of Bizerte, University of Carthage, 7021 Bizerte, Tunisia.
}

How to cite this paper: R. Saidi, A. Gritli, M. Ben Rhaiem, I. Mnejja, B. Jemli. (2021) Fungal Contaminants of Spices Used in Tunisia. International Journal of Food Science and Agriculture, 5(4), 698-703.

DOI: 10.26855/ijfsa.2021.12.018

Received: October 15, 2021

Accepted: November 10, 2021

Published: December 8, 2021

*Corresponding author: R. Saidi, Military Laboratory of Food Analysis, General Directorate of Military Health, 2001 Tunis, Tunisia; Department of Biology, Faculty of Sciences of Bizerte, University of Carthage, 7021 Bizerte, Tunisia.

Email: raedsaidi@yahoo.com

\begin{abstract}
Spices are used extensively not only to flavor foods but also for their medicinal properties. To date, no data are available regarding the nature of the toxigenic fungal species that may contaminate these products marketed in Tunisia. The aim of this study was to investigate the natural occurrence of fungi in commonly consumed spices collected from different military catering. A total of 213 samples representing five kinds of spices (Curcuma, red pepper, coriander, caraway and cumin) were tested for the total fungal count following a standardized dilution method. Fungal isolates were identified according to morphological and microscopic characteristics. Fungal contamination showed a large variation, about $88 \%$ of total spices samples were infected with fungi. The highest level of contamination ( $\geq 5 \log _{10}$ CFU/g) was observed in red pepper and caraway samples. Three fungal genera were identified: Aspergillus spp (36.1\%), Mucor spp (28.2\%) and Penicillium spp (1\%). Aspergillus genus was present in $50 \%$ of curcuma samples and $48 \%$ of coriander samples while it was too low in cumin samples with $16.6 \%$. A total of 95 strains of five Aspergillus species were identified with the dominance of Aspergillus niger (61\%) and Aspergillus flavus (30\%). Aspergillus niger were present in all spices kinds while Aspergillus flavus prevalence was $32 \%$ in curcuma samples, $12 \%$ in coriander samples, $10 \%$ in red pepper samples and less present in cumin and caraway samples (0.5\%).
\end{abstract}

\section{Keywords}

Spices, Fungi, Aspergillus, Tunisia

\section{Introduction}

Spices are natural products obtained from parts of several plant species, they are widely used in food preparation. In Tunisia, as in all Mediterranean countries, spices are frequently used to flavor foods but also for their medicinal properties. As with many other agricultural products, spices and herbs may be exposed to a wide range of microbial contamination during pre- and post-harvesting. Moreover, the contamination may occur during processing storage, distribution, sale and/or use [1]. Fungi are considered to be the main contaminants of spices [2]. In addition, because of possible neglects during processing, food containing spices are more likely to be deteriorated and could be toxic to humans due to mycotoxins that are produced by some fungal species [3]. Spices are frequently heavily contaminated with xerophilic storage moulds and bacteria [4-5]. Aspergillus and Penicillium are the most frequent fungal contaminants of spices [3]. Other species of moulds are frequently isolated from spices, including Scopulariopsis and Sporendonema [6]. Aspergillus, Penicillium, and Fusarium genera are the most common fungi contaminant of spices [3]. In Tunisia, there is not yet any work which is interested in the study of the fungal flora which contaminates spices but rather there are many publications about mycotoxins in spices. 
Ghali et al. [7] reported that the contamination frequency of Ochratoxin A in spices commercialized in Tunisia such as, red pepper, cumin and black pepper was $57.1 \%$. More recently, they found that about $69.2 \%$ of spice samples contained aflatoxins with a high occurrence of Aflatoxin B1 [8].

Therefore, the aim of this study was to investigate the natural occurrence of toxigenic fungi in commonly consumed spices in Tunisia and give baseline information on their safety and to help us conduct further studies.

\section{Materials and Methods}

\subsection{Sampling}

Samples from five types of spices (curcuma, red pepper, coriander, caraway and cumin), widely used in Tunisian food preparation were collected. A total of 213 dried and ground spices samples from different military caterings covering the whole country were collected in sterile identified polyethylene bags and then placed in clean containers of inert material, protected against contamination and damage resulting from transport.

\subsection{Mycological study}

\subsubsection{Total moulds counts}

All media and reagents were purchased from Biokar Diagnostics (Allonne, France). Serial dilutions method, according to the standard [9] was used to determine total fungal counts on Sabouraud chloramphenicol Agar medium (Peptic digest of Meat $10 \mathrm{~g} / \mathrm{l}$, Glucose $20 \mathrm{~g} / \mathrm{l}$, Chloramphenicol $0.5 \mathrm{~g} / \mathrm{l}$, Bacteriological agar $15 \mathrm{~g} / \mathrm{l}$, pH of the ready-to-use media at $25^{\circ} \mathrm{C}: 5.7 \pm 0.2$ ). Ten grams of each sample were added to $90 \mathrm{ml}$ of Tryptone Salt Broth (Tryptone $1 \mathrm{~g} / \mathrm{l}$, Sodium chloride $8.5 \mathrm{~g} / \mathrm{l}, \mathrm{pH}$ of the ready-to-use media at $25^{\circ} \mathrm{C}: 7.0 \pm 0.2$ ) in $250 \mathrm{ml}$ sterile glass bottle with sterile glass beads of $5 \mathrm{~mm}$ diameter to facilitate the manual homogenization for $30 \mathrm{~min}$. The spice-water suspension was allowed to stand for 10 min with intermittent shaking before being plated then tenfold serial dilution were prepared. Petri dishes containing $15 \mathrm{ml}$ of Sabouraud medium were surface inoculated with $100 \mu \mathrm{L}$ portion of each dilution in duplicates. The serial dilution method was used to determine total fungal counts. Plates were incubated at $25 \pm 1{ }^{\circ} \mathrm{C}$ for 7 days and examined for the growth of moulds daily. Fungal colonies were examined visually and microscopically and colonies counted as colony forming units per gram (CFU/g). Pure colonies of fungal isolates were obtained by sub-culturing on similar media at $28 \pm 1^{\circ} \mathrm{C}$ and were characterized based on their macroscopic and microscopic characteristics. The fungal isolates were transferred to sterile plates for purification and identification, only fungal species with medical significance were identified.

\subsubsection{Fungal contamination levels}

Scale with five levels of contamination was established which covers a range from Level 1 corresponding to a total fungal count $<2 \log _{10} \mathrm{CFU} / \mathrm{g}$ to level 5 corresponding to a total fungal count $>5 \log _{10} \mathrm{CFU} / \mathrm{g}$ (Table 1).

\section{Results}

A total of 213 samples of five different spices samples were analysed for fungi contamination by dilution plating. The majority (88\%) of spices samples were contaminated with at least one fungus. All red pepper samples were contaminated with fungi (Figure 3). The highest level of fungal contamination (level 5) was observed in six samples of red pepper and one sample of coriander (Table1, Figure 1). The level 3 of contamination was frequent in the samples of red peppers, caraway and coriander which present (30\%) of total samples (Figure 1). Cumin samples are the less contaminated by fungi since $38 \%$ of samples were at level 1 . Three principal fungal genera were identified namely: Aspergillus spp (36\%), Mucor spp (28\%), Penicillium spp (1\%) (Figure 2). Aspergillus was frequent in curcuma (50\%), coriander (46\%), caraway (39\%) and red pepper (26\%) of samples, while it was low in cumin samples (16.6\%) (Figure 3). However, Penicillium was detected only in tow samples of red pepper and caraway (1\%) (Fig.3). A total of95 strains of five Aspergillus species were identified: Aspergillus niger (58 strains), Aspergillus flavus (29 strains), Aspergillus nidulans (5 strains), Aspergillus versicolor (2 strains) and Aspergillus terreus (1 strain) (Table 2). Aspergillus niger and Aspergillus flavus were the most frequent species with respectively $60 \%$ and $30 \%$ of total identified species. Aspergillus niger was present in coriander and caraway (36\%), in curcuma (32\%), in red pepper (26\%) while it was low in cumin (14\%) (Figure 4). On the other hand, Aspergillus flavus was highly present only in curcuma (32\%), coriander (12\%) and red pepper (10\%), while it was less present in cumin and caraway samples $(0.5 \%)$. 


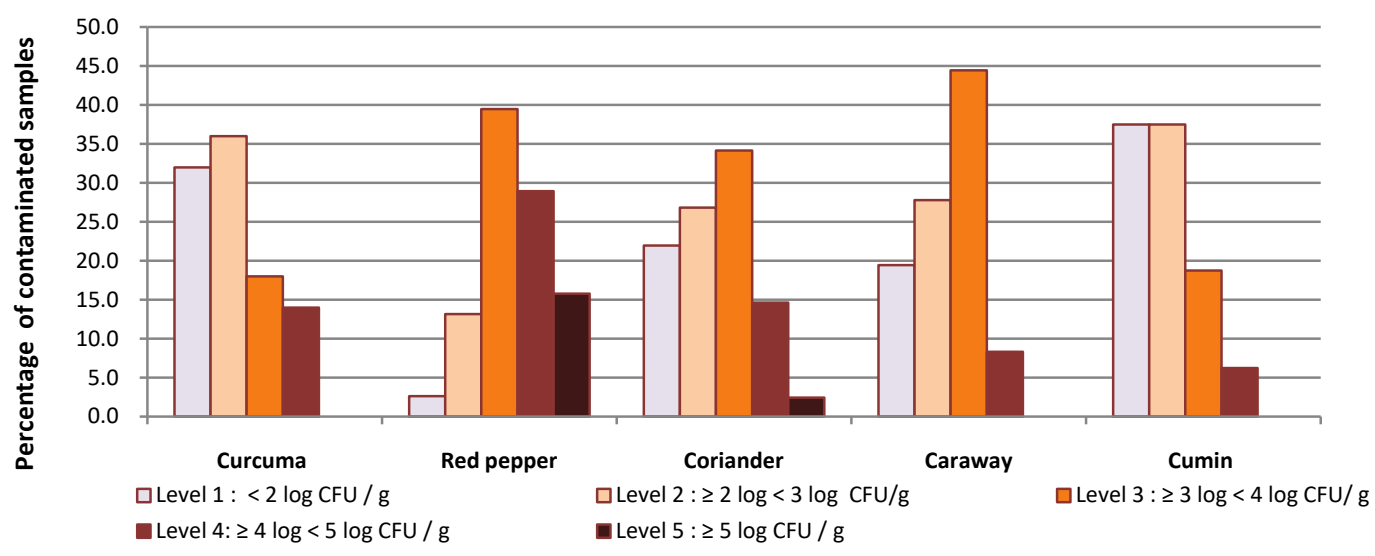

Figure 1. Distribution of fungal contamination levels by kinds of spices.

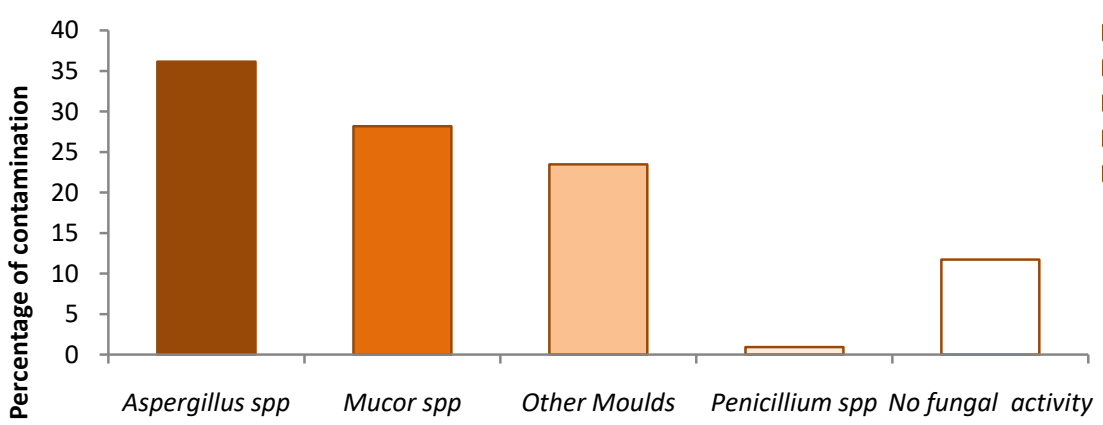

$$
\begin{aligned}
& \square \text { Aspergillus spp } \\
& \square \text { Mucor spp } \\
& \square \text { Other Moulds } \\
& \square \text { Penicillium spp } \\
& \square \text { No fungal activity }
\end{aligned}
$$

Figure 2. Main fungal genera present in spices samples.

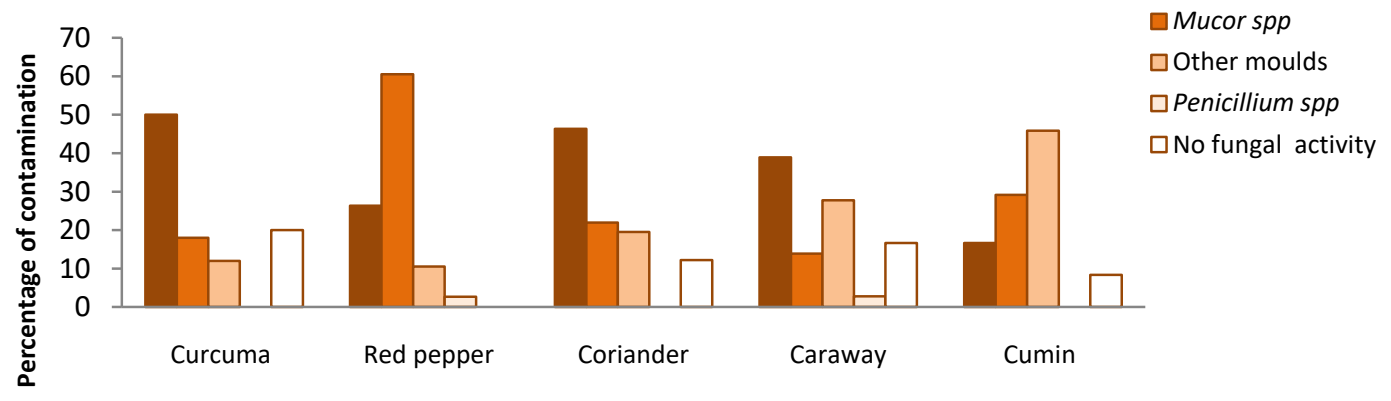

Figure 3. Identification of fungal flora present in spices samples.

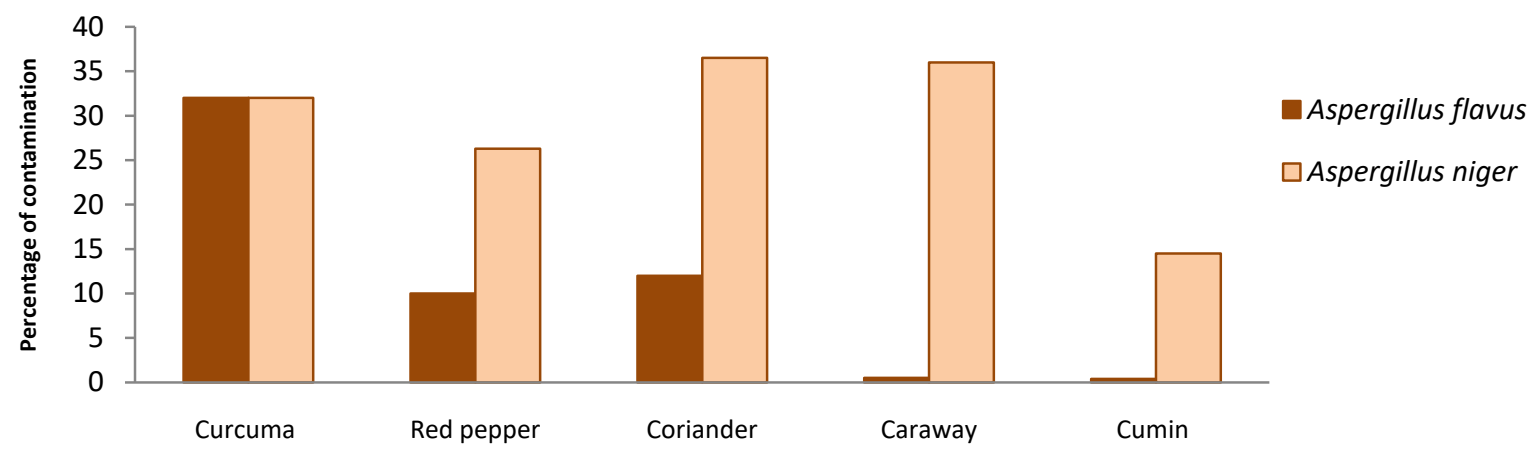

Figure 4. Contamination of spices samples by Aspergillus flavus and Aspergillus niger. 
Table 1. Scale used to classify total fungal contamination into five levels

\begin{tabular}{cccccc}
\hline Contamination levels & L1 & L2 & L3 & L4 & L5 \\
\hline Fungal counts (CFU/g) & $<2 \log _{10}$ & $\geq 2 \log _{10}<3 \log$ & $\geq 3 \log _{10}<4 \log$ & $\geq 4 \log _{10}<5 \log$ & $\geq 5 \log _{10}$ \\
\hline
\end{tabular}

Table 2. Number of Aspergillus species isolated from spices samples

\begin{tabular}{cccccc}
\hline \multicolumn{7}{c}{ Isolated Aspergillus species } \\
\hline Spices & A. flavus & A. niger & A. nidulans & A. terreus & A. versicolor \\
\hline Curcuma & 16 & 16 & 3 & 1 & 1 \\
\hline Red pepper & 4 & 10 & 0 & 0 & 0 \\
\hline Coriander & 5 & 16 & 2 & 0 & 0 \\
\hline Caraway & 2 & 13 & 0 & 0 & 0 \\
\hline Cumin & 2 & 3 & $\mathbf{5}$ & $\mathbf{1}$ & $\mathbf{2}$ \\
\hline Total & $\mathbf{2 9}$ & $\mathbf{5 8}$ & & 0
\end{tabular}

\section{Discussion}

The high contamination of spices with fungi was given by several researchers such as Punam and Dhiraj [10] who revealed the wide range of fungal contamination in spices. As well as the high fungal contamination of red pepper which was reported by Bokhari [11] when the red pepper samples were relatively the richest in total number of fungi (average of 5 samples was 2,682.4 colonies per $\mathrm{g}$ fresh weight) and those reported by Azzoune et al. [12] that the most contaminated spices are ginger, sweet pepper, red pepper, sweet cumin and saffron.

$30 \%$ of total samples were at the Level 3 of fungal contamination ( $\geq 3 \log _{10} \leq 4 \log _{10}$ CFU /g) (Figure 1). This level was usually reported [13]. Recently, Makhlouf et al. [14] found that the overall mean fungal contamination was 7.6 $\times 10^{3} \mathrm{CFU} / \mathrm{g}$, and most spices displayed a moderate mean fungal load that ranged from $10^{3}$ to $4 \times 10^{3} \mathrm{CFU} / \mathrm{g}$.

$38 \%$ of cumin samples are at level 1 of fungal contamination which is similar to results reported by Bhat et al. [15] that no fungi were found in the cumin seed samples sold in retail shops in the city of Bombay. One year later, Garrido et al [16] evaluated the fungi contaminated of 33 different commercial spices and reported that only nutmeg, anise, tarragon and cumin showed very low fungal contamination. This result was later confirmed by Azzoune et al [12] when they found that aniseed, black pepper, coriander, caraway, cumin and cinnamon, consumed in Algeria, are relatively less contaminated by fungi.

Three principal fungal genera were identified: Aspergillus spp, Mucor spp, Penicillium spp. Our results were consistent with those reported by Azzoune et al. [12] that the commonly isolated fungi were species of Aspergillus (56.4\%), Penicillium (25.1\%), Mucor (12.8\%) and Eurotium (5.7\%). Confirmed later by Makhlouf et al. [14] when identification of the fungal genera found in spices showed that Aspergillus was the most frequent genus (76\%), followed, in decreasing order, by Mucorales (36\%), Penicillium (30\%) and Fusarium (7.5\%).

Srivastava and Chandra [17] studied the mycobiota of 4 kinds of spices (coriander, cumin, fennel and fenugreek) in India and reported that Aspergillus followed by Fusarium were the most frequent genera. Bhat et al. [15] tested the microbial profile of cumin seeds and chilli powder sold in retail shops in the city of Bombay and reported that Aspergillus was the predominant genus in chilli powder samples. Also, they reported that no fungi were found in the cumin seed samples examined. El-Kady et al [18] isolated 38 genera and 81 species from 120 samples of 24 kinds of spices collected from different places at Assiut Governorate, Egypt. They reported that the predominant genera were Aspergillus (25 species) and Penicillium (7 species) of which Aspergillus flavus, Aspergillus niger, Penicillium chrysogenum and Penicillium corylophilum were the most commonly occurring.

The incidence of Penicillium genus in studied spices was too low (1\%) (Figure 3) comparing with results reported by Azzoune et al. [12] and Makhlouf et al. [14] when Penicillium incidence was 25.1\% and 30\% respectively.

The dominance of both Aspergillus niger and Aspergillus flavus species with respectively $60 \%$ and $30 \%$ of prevalence in all spices samples was in agreement with results found by Aiko and Mehta [19] when Aspergillus niger was found to be the most commonly occurring contaminant and was isolated from 42 (66.66\%) samples. Same results reported by Hashem and Alamri [20], when Aspergillus niger and Aspergillus flavus had the highest occurrence remarks and emerged between $93 \%$ and $46.7 \%$ of samples, respectively. However, Garrido et al. [16] reported that Aspergillus flavus was found to be a predominant component of the spices mycobiota. El Mahgubi et al. [21] also observed a wide- 
spread contamination of paprika, cumin and pepper marketed in Morocco by Aspergillus flavus with 57\% of isolates.

Aspergillus flavus specie was less present in cumin and caraway samples $(0.5 \%)$. This can be explained by the effect of the matrix composition which can promote the growth of Aspergillus flavus in the turmeric, coriander and red pepper samples, and inhibit it in the caraway and cumin samples. Studies have revealed that secondary metabolites of many plants are able to prevent the growth of fungi [22]. Moghadam et al. [23] indicated that Cinnamon, Clove, Thyme, Zataria, Cumin and Caraway essential oils have antifungal activity against Aspergillus ochraceus.

\section{Conclusion}

Mycological study carried out on 213 samples, representing five kinds of spices (Curcuma, red pepper, coriander, caraway and cumin) show that fungal contamination was very high. Aspergillus was the most frequent genus detected with the dominance of two species Aspergillus niger and Aspergillus flavus. Cumin samples are the least contaminated by fungi including Aspergillus genera which can be explained by the ability of this spice to inhibit fungi.

Following these results, other additional studies will be carried out such as the search for mycotoxins in these spices, the study of the antifungal activity of cumin and the explanation of the low incidence of the Penicillium genera in the spices consumed in Tunisia.

\section{Acknowledgements}

We would like to thank all the staff of the Parasitology and Mycology Service of the Military Hospital of Instruction of Tunis particularly Professor Saadia Gargouri.

\section{References}

[1] McKee, L. H. (1995). Microbial contamination of spices and herbs: A review. LWT—Food Science and Technology, Volume 28, Issue 1, 1-11.

[2] Kneifel, W. and Berger, E. (1994). Microbial criteria of random samples of spices and herbs retailed on the Austrian market. J. Food Prot., 57, 893-901.

[3] Kocić-Tanackov, S. D., Dimić, G. R., and Karalić, D. (2007). Contamination of spices with moulds potential producers of sterigmatocystine. Acta Periodica Technologica, (38), 29-35.

[4] Dimić, G., Škrinjar, M., Došen-Bogićević, V. (2000). Moulds, potential producers of sterigmatocystin in spices. Tehnologija Mesa, 2000, Vol. 41, No.4/6, pp. 131-137 ref.31.

[5] Romagnoli, B., Menna, V., Gruppioni, N., and Bergamini, C. (2007). Aflatoxins in spices, aromatic herbs, herbs-Teas and medicinal plants marketed in Italy. Food Control, 18: 697-701.

[6] Zinedine, A., Brera, C., Elakhdari, S., Catano, C., Debegnach, F., Angelini, S., De Santis, B., Faid, M., Benlemlih, M., Minardi, V., and Miraglia, M. (2006). Natural occurrence of mycotoxins in cereals and spices commercialized in Morocco. Food Control, 17: 868-874.

[7] Ghali, R., Hmaissia-khlifa, K., Ghorbel, H., Maaroufi, and Hedili, A. (2008). Incidence of aflatoxins, ochratoxin A and zearalenone in tunisian foods. Food Control, Volume 19, Issue 9, pp. 921-924.

[8] Ghali, R., Hmaissia-khlifa, K., Ghorbel, H., Maaroufi, K., and Hedili, A. (2010). Aflatoxin determination in commonly consumed foods in Tunisia. Journal of the Sciences of Food and Agriculture, 90: 2347-2351.

[9] Norme Française, N. F. (2002). Microbiology of food animal feeding stuffs_-Enumeration of yeasts and moulds by colony-count technique at $25^{\circ} \mathrm{C}$ - Routine method. NF.V08-059 November2002.

[10] Punam Jeswal and Dhiraj Kumar. (2015). Mycobiota and Natural Incidence of Aflatoxins, Ochratoxin A, and Citrinin in Indian Spices Confirmed by LC-MS/MS. International Journal of Microbiology, v. 2015, p. 8.

[11] Bokhari, F. M. (2007). Spices mycobiota and mycotoxins available in Saudi Arabia and their abilities to inhibit growth of some toxigenic fungi. Korean Soc. Mycol., 35(2): 47-53.

[12] Azzoune, N., Mokrane, S., Riba, A., Bouras, N., Carol, V., Sabaou, N., and Mathieu, F. (2015). Contamination of common spices by aflatoxigenic fungi and aflatoxin B1 in Algeria. Quality Assurance and Safety of Crops \& Foods, Wiley-Blackwell, 2015, 8(1), pp. 137-144.

[13] Dimić, G. R., Kocić-Tanackov, S. D., Tepić, A. N., Vujičić, B. L., and Šumić, Z. M. (2008). Mycopopulation of spices. Acta Periodica Technologica, (39), 1-9.

[14] Makhlouf, J., Carvajal-Campos, A., Querin, A., Tadrist, S., Puel, O., Lorber, S., and Bailly, S. (2019). Morphologic, molecular and metabolic characterization of Aspergillus section Flavi in spices marketed in Lebanon. Scientific Reports, 9(1), 1-11.

[15] Bhat, R., Geeta, H., and Kulkarni, P. R. (1987). Microbial profile of cumin seeds and chilli powder sold in retail shops in the 
city of Bombay. J. Food Protect., 50: 418-419.

[16] Garrido, M. D., Jordano, R., Martinez, P., Jordal, M., and Pozo, R. (1988). Fungal contamination of commercial spices. Alimentaria, 25(189), 81-84.

[17] Srivastava, R. K. and Chandra, S. (1985). Studies on seed mycoflore of some spices in India: Qualitative and quantitative estimations. International Biodeterioration, 21: 19-26.

[18] El-Kady, S., El-Maraghy, S. M., and Mostafa, E. M. (1992). Contribution of the mesophilic fungi of different spices in Egypt. Mycopathologia, 120: 93-101.

[19] Aiko, V. and Mehta, A. (2016). Prevalence of toxigenic fungi in common medicinal herbs and spices in India. 3 Biotech, 6(2), 159.

[20] Hashem, M. and Alamri, S. (2010). Contamination of common spices in Saudi Arabia markets with potential mycotoxin-producing fungi. Saudi Journal of Biological Sciences, 17(2), 167-175.

[21] El Mahgubi, A., Puel, O., Bailly, S., Tadrist, S., Querin, A., Ouadia, A., Oswald, I. P., and Bailly, J. D. (2013), Distribution and toxigenicity of Aspergillus section Flavi in spices marketed in Morocco. Food Control, 32: 143-148.

[22] Ynalvez, R. A., Compean, K. L., Addo-Mensah, A. (2018). Qualitative Determination of the Secondary Metabolites and Evaluation of the Antimicrobial Activity of Leaf Extractsfrom Different Plant Families (Boraginaceae, Fabaceae, Lamiaceae andLauraceae) against Microorganisms of Clinical Importance. Journal of Pharmaceutical Research International, $2018,1-12$.

[23] Moghadam, Z. A., Hosseini, H., Hadian, Z., Asgari, B., Mirmoghtadaie, L., Mohammadi, A., Shamloo, E., and Javadi, N. (2019). Evaluation of the antifungal activity of cinnamon, clove, thymes, zataria multiflora, cumin and caraway essential oils against Ochratoxigenic Aspergillus ochraceus. Journal of Pharmaceutical Research International, v. 26, n. 1, p. 1. 